\title{
PENGARUH PEMBERIAN KREDIT TERHADAP RETURN ON ASSET PADA PT BANK RAKYAT INDONESIA (PERSERO), TBK CABANG SERPONG PERIODE TAHUN 2010-2020
}

\author{
${ }^{1 *}$ Ahmad Syarief Iskandar, ${ }^{2}$ Ana Wijandari, ${ }^{3}$ Nurjaya \\ ${ }^{1}$ IAIN Palopo, Kota Palopo, Sulawesi Selatan, Indonesia \\ 2STEBIS Bina Mandiri, Cileungsi, Bogor, Indonesia \\ ${ }^{3}$ Universitas Suryakancana, Cianjur, Jawa Barat, Indonesia \\ *ahmadsyariefiskandar@iainpalopo.ac.id
}

\begin{abstract}
Abstrak
Penelitian ini bertujuan untuk mengetahui pengaruh Pemberian Kredit terhadap Return On Asset pada PT. Bank Rakyat Indonesia (Persero), Tbk Cabang Serpong. Metode yang digunakan adalah explanatory research. Teknik analisis menggunakan analisis statistik dengan pengujian regresi, korelasi, determinasi dan uji hipotesis. Hasil penelitian ini variabel Pemberian Kredit diperoleh nilai rata-rata sebesar 417,90 milyar\%. Variabel Return On Asset diperoleh nilai rata-rata 5,40\%. Pemberian Kredit berpengaruh positif dan signifikan terhadap Return On Asset dengan nilai persamaan regresi $Y=2,345$ $+0,007 \mathrm{X}$, dan nilai koefisien korelasi 0,744 atau memiliki tingkat hubungan yang kuat dengan nilai determinasi 55,4\%. Uji hipotesis diperoleh signifikansi 0,009<0,05.
\end{abstract}

Kata Kunci: Pemberian Kredit, Return on Asset

Abstrak

This study aims to determine the effect of lending on Return On Assets at PT. Bank Rakyat Indonesia (Persero), Tbk Serpong Branch. The method used is explanatory research. The analysis technique uses statistical analysis with regression, correlation, determination and hypothesis testing. The results of this study of the lending variable obtained an average value of 417.90 billion\%. The Return On Assets variable obtained an average value of $5.40 \%$. Credit provision has a positive and significant effect on Return On Assets with a regression equation value of $Y=2.345+0.007 X$, and a correlation coefficient value of 0.744 or has a strong relationship with a determination value of $55.4 \%$. Hypothesis testing obtained a significance of $0.009<0.05$.

Keywords: Lending, Return on Asset

\section{PENDAHULUAN}

\section{Latar Belakang Masalah}

Pada umumnya suatu negara diharapkan dapat meningkatkan perekonomian dalam rangka meningkatkan taraf hidup masyarakatnya melalui adanya kebijakan dibidang perekonomian negara tersebut. Berbagai unsur pembangunan dibidang ekonomi dan keuangan menjadi salah satu faktor penentu perekonomian negara, kegiatan dunia usaha merupakan cerminan perekonomian bagi suatu daerah dalam meningkatkan pendapatan masyarakat. Salah satu unsur kegiatan pembangunan ekonomi dan keuangan adalah lembaga keuangan, lembaga keuangan yang dimaksud adalah bank.

Menurut Undang-Undang RI Nomor 11 tahun 1998 tanggal 10 November 1998 tentang perbankan, bahwa "Bank adalah badan usaha yang menghimpun dana dari masyarakat dalam bentuk simpanan dan menyalurkannya kembali kepada masyarakat dalam bentuk kredit dan atau bentuk-bentuk lainnya dalam rangka meningkatkan taraf hidup rakyat banyak." Bank juga merupakan suatu badan yang berfungsi sebagai financial intermediary atau perantara keuangan antara pemilik dana dengan pengguna dana. 
Dalam kegiatan operasionalnya, bank harus selalu inovatif agar dapat selalu mempertahankan kegiatan usahanya yang bertujuan pada peningkatan taraf hidup rakyat banyak seperti halnya fungsi bank adalah menghimpun dana dari masyarakat dan selanjutnya disalurkan kembali melalui Pemberian Kredit pada masyarakat yang membutuhkannya. Kredit merupakan penyediaan uang atau tagihan berdasarkan persetujuan pinjam meminjam yang mewajibkan untuk melunasinya dalam jangka waktu tertentu dengan pemberian bunga.

Peranan bank sebagai lembaga keuangan tidak pernah lepas dari masalah kredit, berbagai sumber dana yang telah dihimpun oleh bank dari masyarakat sebagian besar dialokasikan untuk kredit. Kegiatan kredit merupakan rangkaian kegiatan utama suatu bank besarnya jumlah kredit yang disalurkan akan menentukan keuntungan bagi bank, karena dengan Pemberian Kredit akan berdampak positif yaitu penambahan dana yang terjadi dari kegiatan pembayaran para nasabah bank.

Pengelolaan kredit bagi sebuah perusahaan adalah suatu hal yang penting untuk dilakukan agar kreditnya berjalan dengan baik dan meminimalkan hal-hal yang mungkin akan terjadi diluar perhitungan. Melakukan pengelolaan kredit berarti melaksanakan fungsi-fungsi manajemen, dimana dalam mengelola atau mengatur kreditnya perlu dilakukan perencanaan yang matang. Kemudian setelah direncanakan maka diorganisasikan, agar perencanaan tersebut lebih terarah. Pelaksanaan pengelolaan kredit dapat meningkatkan keuntungan bagi sebuah perusahaan. Memperoleh keuntungan merupakan tujuan utama berdirinya suatu badan usaha, baik badan usaha yang terbentuk perseroan terbatas (PT), yayasan atau bentuk badan usaha lainnya.

Menurut Kasmir (2010:245) berpendapat bahwa "Kegiatan utama bank adalah menyalurkan dana, maka jika dikatakan bahwa apabila pinjaman meningkat, maka dalam praktiknya akan mampu meningkatkan laba perusahaan. Demikin pula sebaliknya apabila tidak mampu menyalurkan kreditnya, maka bank akan rugi karena beban biaya untuk penimpanan dana tetap harus dibayarkan. Keuntungan yang diterima bank berasal dari selisih bunga pinjaman kepada debitur dengan suku bunga simpanan yang dibayar kepada nasabah penyimpan (Abdullah, 2005:32). Jika kredit yang disalurkan kepada masyarakat semakin besar maka pendapatan yang di terima bank akan meningkat dan akan mempengaruhi besarnya laba yang diterima oleh bank tersebut.

Profitabilitas merupakan kemampuan suatu perusahaan untuk mendapatkan laba (keuntungan) dalam suatu periode tertentu. Pengertian yang sama juga disampaikan oleh Husnan (2001) bahwa profitabilitas adalah kemampuan suatu perusahaan dalam menghasilkan keuntungan (Profit) pada tingkat penjualan, aset, modal saham tertentu. Sedangkan menurut Michelle Megawati (2005) profitabilitas merupakan kemampuan perusahaan menghasilkan laba(profit) yang akan menjadi dasar pembagian deviden perusahaan. Dalam hal penilaian tingkat profitabilitas suatu bank yang diukur dalam aktiva produktif yang sumber dananya berasal dari kredit yang diberikan kepada masyarakat yang dapat membantu bank dalam memaksimumkan profitabilitasnya yang salah satu indikatornya adalah return on assets (Heru Saptono:2008).

Besarnya jumlah kredit yang disalurkan akan menentukan keuntungan yang diperolah. Akan tetapi tidak berarti bahwa jumlah kredit yang disalurkan besar akan 
memberikan keuntungan yang besar pula. Dalam hal ini PT. Bank Rakyat Indonesia (Persero), Tbk atau bank BRI adalah salah satu bank milik pemerintah yang terbesar di Indonesia yang memberikan kontribusi signifikan terhadap perbankan dan perekonomian Indonesia. Bank BRI selalu menerapkan prinsip hati-hati dalam Pemberian Kredit agar laba yang diharapkan oleh bank tersebut terus meningkat, prinsip hati-hati dapat dilihat dari peningkatan pengawasan Pemberian Kredit dan penurunan resiko kredit bermasalah.

Berikut ini data jumlah pemberian kredit yang disalurkan PT. Bank Rakyat Indonesia (Persero), Tbk Cabang Serpong dari tahun 2010 sampai dengan 2020:

Tabel 1. Data Penyaluran Kredit dan Profitabilitas PT. Bank Rakyat Indonesia (Persero), Tbk Cabang Serpong Periode 20102020

\begin{tabular}{|c|c|c|}
\hline Tahun & $\begin{array}{c}\text { Kredit Yang Di } \\
\text { Salurkan } \\
\text { (Rp/Milyar) }\end{array}$ & $\begin{array}{c}\text { Return on } \\
\text { Assets (ROA) } \\
\text { (\%) }\end{array}$ \\
\hline 2010 & 232.85 & 4.38 \\
\hline 2011 & 230.44 & 4.24 \\
\hline 2012 & 344.35 & 4.75 \\
\hline 2013 & 421.55 & 4.84 \\
\hline 2014 & 485.32 & 5.42 \\
\hline 2015 & 575.42 & 8.22 \\
\hline 2016 & 342.32 & 4.85 \\
\hline 2017 & 415.65 & 4.92 \\
\hline 2018 & 469.33 & 6.76 \\
\hline 2019 & 541.48 & 5.88 \\
\hline 2020 & 538.22 & 5.16 \\
\hline $\begin{array}{c}\text { Rata- } \\
\text { rata }\end{array}$ & 417.90 & 5.40 \\
\hline
\end{tabular}

Berdasarkan tabel di atas memperlihatkan bahwa PT. Bank Rakyat Indonesia (Persero), Tbk Cabang Serpong dalam menyalurkan dana dari masyarakat kepada masyarakat dengan cara kredit selama periode 2010-2020 rata-rata sebanyak Rp. 417,90 milyar dengan perolehan rasio Profitabilitas rata-rata pertahun mencapai $5,40 \%$.

Berdasarkan latar belakang diatas maka penulis tertarik untuk mengambil judul penelitian "Pengaruh Pemberian Kredit Terhadap Return on Asset Pada PT. Bank Rakyat Indonesia (Persero) Tbk Cabang Serpong".

\section{Rumusan Masalah}

a. Bagaimana Pemberian Kredit pada pada PT. Bank Rakyat Indonesia (Persero), Tbk Cabang Serpong?.

b. Bagaimana Return On Asset pada PT. Bank Rakyat Indonesia (Persero), Tbk Cabang Serpong ?.

c. Adakah pengaruh antara Pemberian Kredit terhadap Return On Asset pada PT. Bank Rakyat Indonesia (Persero), Tbk Cabang Serpong ?.

\section{Tujuan Penelitian}

a. Untuk mengetahui kondisi Pemberian Kredit pada PT. Bank Rakyat Indonesia (Persero), Tbk Cabang Serpong.

b. Untuk mengetahui kondisi Return On Asset pada PT. Bank Rakyat Indonesia (Persero), Tbk Cabang Serpong.

c. Untuk mengetahui pengaruh antara Pemberian Kredit terhadap Return On Asset pada PT. Bank Rakyat Indonesia (Persero), Tbk Cabang Serpong.

\section{METODE PENELITIAN}

\section{Populasi}

Populasi dalam penelitian ini laporan keuangan PT. Bank Rakyat Indonesia (Persero), Tbk Cabang Serpong selama 11 tahun

\section{Sampel}

Teknik pengambilan sampling dalam penelitian ini adalah samplel jenuh, dimana semua anggota populasi dijadikan sebagai sampel. Dengan demikian sampel dalam penelitian ini laporan keuangan PT. Bank Rakyat Indonesia (Persero), Tbk Cabang Serpong selama 11 tahun.

\section{Jenis Penelitian}

Jenis penelitian yang dipakai adalah asosiatif, dimana tujuannya adalah untuk mengetahui mencari 
keterhubungan antara variabel independen terhadap variabel dependennya

\section{Metode Analisis Data}

Dalam menganalisis data digunakan uji validitas, uji reliabilitas, analisis regresi linier sederhana, koefisien korelasi, koefisien determinasi dan uji hipotesis.
HASIL PENELITIAN

1. Analisis Deskriptif

Pada pengujian ini digunakan untuk mengetahui skor minimum dan maksimum skor tertinggi, ratting score dan standar deviasi dari masing-masing variabel. Adapun hasilnya sebagai berikut:

Tabel 2. Hasil Analisis Descriptive Statistics

Descriptive Statistics

$\mathrm{N}$ Minimum Maximum Mean Std. Deviation

\begin{tabular}{l|r|r|r|r|r|}
\hline Pemberian Kredit 11 & 230.44 & 575.42 & 417.90 & 119.279 \\
\hline Return on Asset & 11 & 4.24 & 8.22 & 5.40 & 1.172 \\
\hline Valid N (listwise) & 11 & & & & \\
\hline
\end{tabular}

Pemberian Kredit diperoleh nilai minimum sebesar 230,44 milyar dan nilai maximum 575,42 milyar dengan rata-rata sebesar 417,90 milyar dengan standar deviasi 119,27.

Return On Asset diperoleh nilai minimum sebesar $4,24 \%$ dan nilai maximum $8,22 \%$ dengan rata-rata sebesar 5,40\% dengan standar deviasi $1,172 \%$.

\section{Analisis Verifikatif}

Pada analisis ini dimaksudkan untuk mengetahui pengaruh variabel independen terhadap variabel dependen. Adapun hasil pengujian sebagai berikut:

\section{a. Analisis Regresi Linier Sederhana}

Uji regresi ini dimaksudkan untuk mengetahui perubahan variabel dependen jika variabel independen mengalami perubahan. Adapun hasil pengujiannya sebagai berikut:

Tabel 3. Hasil Pengujian Regresi Linier Sederhana

$$
\text { Coefficients }^{a}
$$

Unstandardized Standardized

Coefficients Coefficients

\begin{tabular}{|c|c|c|c|c|c|}
\hline Model & B & Std. Error & Beta & $\mathrm{t}$ & Sig. \\
\hline 1 (Constant) & 2.345 & .948 & & 2.474 & .035 \\
\hline Pemberian Kredit $(X)$ & .007 & .002 & .744 & 3.341 & .009 \\
\hline
\end{tabular}

a. Dependent Variable: Return on Asset $(\mathrm{Y})$

Berdasarkan hasil pengujian pada tabel di atas, diperoleh persamaan regresi $Y=2,345+0,007 X$. Dari persamaan tersebut dijelaskan sebagai berikut:

1) Konstanta sebesar 2,345 diartikan jika Pemberian Kredit tidak ada, maka telah terdapat nilai Return On Asset sebesar 2,345 point.

2) Koefisien regresi Pemberian Kredit sebesar 0,007, angka ini positif artinya setiap ada peningkatan Pemberian Kredit sebesar 0,007 point maka Return On Asset juga akan mengalami peningkatan sebesar 0,007 point.

b. Analisis Koefisien Korelasi

Analisis koefisien korelasi dimaksudkan untuk mengetahui tingkt kekuatan hubungan dari variabel independen terhadap variabel dependen baik secara parsial maupun simultan. Adapun hasil pengujian sebagai berikut: 
Tabel 4. Hasil Pengujian Koefisien Korelasi Pemberian Kredit Terhadap Return On Asset.

\begin{tabular}{llr|r} 
& \multicolumn{1}{c}{ Correlations $^{\mathbf{b}}$} & $\begin{array}{c}\text { Pemberian } \\
\text { Kredit }\end{array}$ & Return on Asset \\
\hline Pemberian Kredit & Pearson Correlation & 1 & $.744^{* *}$ \\
\cline { 2 - 4 } & Sig. (2-tailed) & .009 \\
\hline Return on Asset & Pearson Correlation & $.744^{* *}$ & 1 \\
\cline { 2 - 4 } & Sig. (2-tailed) & .009 & \\
\hline
\end{tabular}

**. Correlation is significant at the 0.01 level (2-tailed).

b. Listwise $\mathrm{N}=11$

Berdasarkan hasil pengujian diperoleh nilai korelasi sebesar 0,744 artinya Pemberian Kredit memiliki hubungan yang kuat terhadap Return On Asset.

c. Analisis Koefisien Determinasi

Tabel 5. Hasil Pengujian Koefisien Determinasi Pemberian Kredit Terhadap Return On Asset.

Model Summary

\begin{tabular}{ll|l|l|l|} 
Model R & R Square & Adjusted R Square & Std. Error of the Estimate \\
\hline 1
\end{tabular}

\begin{tabular}{lrrrr}
\hline 1 & $.744^{\mathrm{a}}$ & .554 & .504 & .82564 \\
\hline a. & Predictors: (Constant), Pemberian Kredit (X)
\end{tabular}

Berdasarkan hasil pengujian diperoleh nilai determinasi sebesar 0,554 artinya Pemberian Kredit memiliki kontribusi pengaruh sebesar $55,4 \%$ terhadap Return On Asset.

\section{d. Uji Hipotesis}

Tabel 6. Hasil Uji Hipotesis Pemberian Kredit Terhadap Return On Asset.

\section{Coefficients $^{\mathrm{a}}$}

Unstandardized

Coefficients

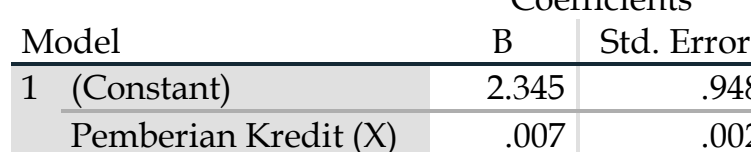

Standardized

Coefficients hipotesis mana yang diterima.

Rumusan hipotesis: Terdapat pengaruh yang signifikan antara Pemberian Kredit terhadap Return On Asset.

a. Dependent Variable: Return on Asset $(\mathrm{Y})$

Berdasarkan hasil pengujian pada tabel di atas, diperoleh nilai $\mathrm{t}$ hitung $>t$ tabel atau $(3,341>2,305)$, dengan demikian hipotesis yang diajukan bahwa terdapat pengaruh yang signifikan atara Pemberian Kredit terhadap Return On Asset diterima.
PEMBAHASAN HASIL PENELITIAN

1. Kondisi Jawaban Responden Variabel Pemberian Kredit

Berdasarkan data empiris dan analisis data, variabel Pemberian Kredit diperoleh nilai rata-rata per tahun sebesar 417,90 milyar\%.

2. Kondisi Jawaban Responden Variabel Return On Asset

Berdasarkan data empiris dan analisis data, variabel Return On Asset diperoleh nilai rata-rata per tahun 
sebesar 5,40\%.

3. Pengaruh Pemberian Kredit Terhadap Return On Asset

Pemberian Kredit berpengaruh signifikan terhadap Return On Asset dengan persamaan regresi $\mathrm{Y}=2,345+$ 0,007X, nilai korelasi sebesar 0,744 atau memiliki hubungan yang kuat dengan kontribusi pengaruh sebesar 55,4\%. Pengujian hipotesis diperoleh nilai $\mathrm{t}$ hitung $>\mathrm{t}$ tabel atau $(3,341>2,305)$. Dengan demikian hipotesis yang diajukan bahwa terdapat berpengaruh signifikan antara Pemberian Kredit terhadap Return On Asset diterima.

\section{KESIMPULAN DAN SARAN}

\section{Kesimpulan}

a. Variabel Pemberian Kredit diperoleh ratting score sebesar 417,90 milyar berada di rentang skala 3,40 - 4,19 dengan kriteria baik atau setuju.

b. Variabel Return On Asset diperoleh ratting score sebesar $5,40 \%$ berada di rentang skala 3,40 - 4,19 dengan kriteria baik atau setuju.

c. Pemberian Kredit berpengaruh signifikan terhadap Return On Asset dengan persamaan regresi $Y=2,345$ $+0,007 X$, nilai korelasi sebesar 0,744 atau kuat dan kontribusi pengaruh sebesar $55,4 \%$ sedangkan sisanya sebesar $57,9 \%$ dipengaruhi faktor lain. Uji hipotesis diperoleh nilai $t$ hitung $>t$ tabel atau $(3,341>2,305)$.

\section{Saran}

a. Sebaiknya PT. Bank Rakyat Indonesia (Persero), Tbk Cabang Serpong selalu memiliki strategi baru dan inovasi baru untuk meningkatkan jumlah Pemberian Kredit agar setiap tahunnya mengalami peningkatan.

b. Sebaiknya PT. Bank Rakyat Indonesia (Persero), Tbk Cabang Serpong mengelola aset yang

dihasilkan dengan baik, karena semakin besar ROA suatu bank, maka semakin besar pula tingkat keuntungan yang dicapai bank tersebut dan semakin baik pula posisi bank tersebut dari segi penggunaan aset.

c. Sebaiknya PT. Bank Rakyat Indonesia (Persero), Tbk Cabang Serpong selalu menjaga keseimbangan antara dana masyarakat yang berhasil dikumpulkan oleh bank dengan jumlah kredit yang diberikan kepada masyarakat atau pihak lainnya agar tidak terjadi dana yang menganggur karena berdasarkan pembahasan Pemberian Kredit merupakan penyumbang besar terhadap peningkatan profitabilitas, hal ini merupakan pengaruh Pemberian Kredit terghadap profitabilitas tersebut.

\section{DAFTAR PUSTAKA}

Abdul Halim. 2013. Analisis Investasi. Edisi 2. Jakarta: Salemba Empat.

Abdullah M. Faisal, 2005, "Manajemen Perbankan: Teknik Analisis Kinerja Keuangan Bank". Cetakan Kelima, Wina UMM Press, Malang

Agus Harjito \& Martono, (2010) "Manajemen Keuangan" Yogyakarta: Penerbit Ekonisia.

Agus Sartono. (2010). "Manajemen Keuangan Toeri dan Aplikasi", Edisi keempat, Yogyakarta: Penerbit BPFE.

Algifari. (2015). “Analisis Regresi untuk Bisnis dan Ekonomi". Yogyakarta: BPFE.

Arikunto, Suharsimi (2014). "Prosedur Penelitian Suatu Pendekatan Praktek". Jakarta: Rineka Cipta.

Astuti, A. M. Dewi, "Manajemen Keuangan Perusahaan". Ghalia Indonesia, Jakarta 2004.

Bambang Riyanto, (2011). “Dasar-dasar Pembelanjaan Perusahaan". Edisi ke empat, BPFE Yogyakarta.

Darmadji, T.H.M Fakhrudin. 2012. Pasar Modal di Indonesia Pendekatan Tanya Jawab. Salemba Empat, Jakarta.

Darsono, 2009. "Manajemen Keuangan". Nusantara Consulting, Jakarta. 
Dendawijaya, Lukman, 2009, "Manajemen Perbankan". Ghalia Indonesia, Jakarta Dumilah, R. et al (2021). Pengaruh Likuiditas Dan Profitabilitas Terhadap Struktur Modal Pada PT Mayora Indah, Tbk Periode 20102019. Jurnal Neraca Peradaban. 1(3) 237-245

Fahmi, Irham (2012), “Pengantar Manajemen Keuangan" Cetakan pertama. Bandung: Penerbit Alfabeta.

Hanadelansa, H., et al. (2019). Analisis Audit Operasional Atas Pemberian Kredit Pemilikan Rumah Pada PT Bank Rakyat Indonesia (Persero) Tbk Kantor Cabang Panakukkang Di KotaMakassar. SENTRALISASI, 8(1), 33-42.

Harahap, Sofyan Syafri, 2007. "Teori Akuntansi: Laporan Keuangan", Penerbit PT. Bumi Aksara, Jakarta.

Hartono, Jogiyanto. 2008. Teori Portofolio Dan Analisis Investasi. Yogyakarta: BPFE.

Hermuningsih, Sri. 2012. Pengantar Pasar Modal Indonesia. Yogyakarta: UPP STIM YKPN.

Horne James C. Van dan John M. Wachowicz. 2012. Prinsip-Prinsip Manajemen Keuangan. alih bahasa Dewi Fitriasari dan Deny A. Kwary. Jakarta: Salemba Empat.

Houston, Brigham, 2010. "Dasar - Dasar Manajemen Keuangan", Edisi 11, Salemba Empat, Jakarta.

Husnan, Suad 1989. "Pembelajaran Perusahaan (Dasar - Dasar Manajemen Keuangan)", Edisi 3. Liberty Yogyakarta, Yogyakarta. Irawati, Susan, "Manajemen Keuangan". Pustaka, Bandung, 2006.

Imam Ghozali (2017). “Aplikasi Analisis Multivariate Dengan Program SPSS". Edisi Kelima. Semarang: Badan Penerbit Undip.

Istijanto (2014) "Riset Sumber Daya Manusia". Jakarta: PT. Gramedia Pustaka

Kasmir. (2012) “Pengantar Manajemen
Keuangan", Edisi Pertama, Cetakan kedua, Jakarta: Prenada Media.

Kountur, Ronny, 2009. "Metode penelitian". Cetakan 2, PPM: Jakarta.

Martono dan Agus Harjito, (2011). "Manajemen Keuangan", Jakarta: Penerbit Ekonisia.

Munawir (2010), “Analisis Laporan Keuangan", Edisi Ke Empat, Penerbit Liberty, Yogyakarta.

Najibullah, N., \& Nurjaya, N. (2021). Pengaruh non Performing Financing dan Financing to Deposit Ratio terhadap Pembiayaan pada Bank DKI Syariah. Jurnal Neraca Peradaban, 1(1), 48-55.

Pangaribuan, H., et al. (2021). The Financial Perspective Study on Tax Avoidance. Budapest International Research and Critics Institute (BIRCIJournal): Humanities and Social Sciences, 4(3), 4998-5009.

Rivai, Veithzal, dkk, 2007, "Bank And Financial Institution Management Conventional \& Sharia System", Edisi Pertama, Penerbit PT. RajaGrafindo Persada, Jakarta

Santoso, Singgih (2015). "Menguasai Statistik Multivariat". Jakarta: PT Elex Media Komputindo.

Sartono, "Manajemen Keuangan Aplikasi Dan Teori", Edisi Keempat, BPFE, Yogyakarta, 2008.

Sawir, (2003). “Analisis Kinerja Keuangan dan Perencanaan Keuangan Perusahaan", Cetakan ketiga, Jakarta: Penerbit PT. Gramedia Pustaka Utama.

Sugiyarso, G. dan F. Winarni, “Manajemen Keuangan (Pemahaman Laporan Keuangan, Pengelolaan Aktiva, Kewajiban dan Modal serta Pengukuran

Sugiyono (2017), “Metode Penelitian Administrasi : dilengkapi dengan Metode R \& D". Bandung: Alfabeta. Wardiah, Mia Lasmi, 2013. "Dasar-dasar perbankan". Catakan 1, Pustaka Setia, Bandung. 